\title{
MAGNETIC GUIDANCE OF ORGANISMS
}

\author{
Richard B. Frankel
}

Francis Bitter National Magnet Laboratory, Massachusetts Institute of Technology, Cambridge, Massachusetts 02139

\section{INTRODUCTION}

Human beings have used magnetic compasses as navigation aids since at least the eleventh century AD $(55,63)$. The magnetic compass facilitated long-distance navigation on the high seas and was one of the technological advances that led to the great European voyages of discovery in the thirteenth and fourteenth centuries. The invention of the magnetic compass is usually credited to the Chinese (55), who discovered over 2000 years ago that certain pieces of naturally occurring magnetite $\left(\mathrm{Fe}_{3} \mathrm{O}_{4}\right)$, a common mineral, would orient in astronomically significant directions when allowed to rotate by flotation or pivoting. How the magnetic compass worked was not explained until 1600, when William Gilbert of Colchester published his theory, based on his study of magnetized needles and small spheres of magnetite, that the earth itself is a giant magnetic dipole (27).

Evidence has accumulated that the earth's magnetic dipolar field may also play a role in the orientation, navigation, and homing of a wide variety of organisms including bacteria $(7,8)$, algae (46), snails (13), planaria (14), honey bees $(28,50)$, salmon $(60)$, salamanders $(57)$, homing pigeons $(28,68)$, robins (74), mice $(51)$, and possibly humans $(2,3,30)$. In addition, training experiments on pigeons (12), skates (36), and tuna (M. M. Walker and J. Kirschvink, private communication) have demonstrated the ability of these organisms to sense magnetic fields. Two interaction mechanisms have been elucidated: $(a)$ detection by the organism of the electric field induced by the Faraday effect as the organism moves through the magnetic field; $(b)$ interaction of the magnetic field with magnetic material in the organism. 


\section{Magnetic Induction}

The magnetic induction, or Faraday effect, mechanism is apparently operative in marine sharks, skates, and rays, which are sensitive to electric fields as low as $0.005 \mu \mathrm{V} / \mathrm{cm}$ in seawater (35). The animals detect electric fields through the ampullae of Lorenzini, which are long conductive channels that connect electrically sensitive cells in the snout with pores on the skin. The flow of ocean currents and the motion of the animal through the geomagnetic field induce voltage gradients with sign and magnitude that depend on orientation and that are in general above the animal's sensitivity threshold. Kalmijn (37) demonstrated that skates could b. trained to use magnetic fields of the order of the geomagnetic field as an orientational cue. Brown et al (15) used electrophysiological measurements to show that the ampullae of Lorenzini can detect variations in the geomagnetic field. Jungerman \& Rosenblum (34) have considered the possibility of the magnetic induction mechanism for an animal moving in air. They concluded that a circular, electrically conducting loop millimeters in size would be required to overcome thermal noise, with voltages induced by changes in magnetic flux in the loop as the animal changes its heading.

\section{Magnetic Material in Organisms}

Evidence for orientation by the second mechanism was obtained for homing pigeons in the classical experiment of Keeton (39). He glued small bar magnets to the backs of the heads of a group of homing pigeons and compared their homing ability with that of a group of control birds carrying brass weights. Under sunny skies both groups oriented and homed equally well when released from unfamiliar sites many miles from the home loft; but under overcast skies when the birds could not see the sun, the orientation of the birds carrying magnets was disrupted whereas control birds oriented normally. Subsequently, Walcott \& Green (70) used Helmholtz coils attached to pigeons' heads to change the orientation of the birds under overcast conditions. The orientation depended on the direction of the magnetic field, as determined by the direction of current in coils. Pigeon orientation is also affected by magnetic anomalies and magnetic storms $(40,67)$. These observations suggest that in addition to a magnetic compass a homing pigeon may have a magnetic "map" $(29,68)$. The experimental situation has been reviewed by Walcott $(68)$, Gould $(28,29)$, and $A$ ble (1). Magnetic effects in orientation of migratory birds have been reviewed by Able (1) and Wiltschko (73). Although attempts to observe magnetic sensitivity of pigeons by cardiac response have not been successful, Bookman (12) was able to train pigeons to detect the presence of magnetic fields in a flight cage. 
Birds possess magnetic material that could act as a magnetic sensor. Walcott et al (69) dissected pigeons with nonmagnetic tools and found inducible magnetic remanence in head and neck sections. Magnetic material was localized in a piece of tissue between the dura and the skull. Each pigeon had inducible remanence of $10^{-5}$ to $10^{6} \mathrm{emu}$, which disappeared at $575^{\circ} \mathrm{C}$, indicating the presence of $\mathrm{Fe}_{3} \mathrm{O}_{4}$. Presti \& Pettigrew (58) found magnetic material in the neck musculature of pigeons and migratory white crowned sparrows but did not find localized magnetic materials in the heads. It is likely, but not yet proven, that there is a connection between the magnetic material and magnetic sensitivity. Elucidation of anatomical structure is clearly required. Yorke (75), Kirschvink \& Gould (44), and Presti \& Pettigrew (58) have speculated on the role of $\mathrm{Fe}_{3} \mathrm{O}_{4}$ in a magnetic sensor. Yorke points out that, if a pigeon can somehow measure the total magnetization of its ensemble of magnetic particles, there is enough magnetic material present to indicate the field direction with high accuracy.

A possible connection between $\mathrm{Fe}_{3} \mathrm{O}_{4}$ and magnetic field effects on behavior is also found in honey bees. The behavioral effects have been reviewed by Martin \& Lindauer (50) and Gould (28). Honey bee workers communicate the location of a food source to other workers in a hive by means of a "waggle dance" on a vertical honeycomb. The angle between the direction of the dance and the vertical direction indicates the angle between the food source and the sun. There are consistent errors (missweissumgen) in the dance angle, which vanish when the magnetic field in the hive is nulled by means of external coils. In anomalous situations where bees are made to dance on horizontal surfaces, after an initial period of disorientation they dance along the eight magnetic compass directions (N, NE. E, SE, etc) $(28$, $42,50)$. If the field in the hive is nulled, the dances become disoriented again. There is also evidence that bees can use the diurnal variations in the geomagnetic field to set their circadian rhythms (50).

Gould et al (31) have found that honey bees also contain $\mathrm{Fe}_{3} \mathrm{O}_{4}$. They measured an average induced magnetization of about $2 \times 10^{-6}$ emu per bee, distributed between single-domain and superparamagnetic sized particles, mostly localized to the abdomen. Recently, Kuterbach et al (45) have found bands of cells around the abdominal segments that contain numerous iron-rich granules. The granules are primarily a hydrous iron oxide, which can be a precursor in the precipitation of $\mathrm{Fe}_{3} \mathrm{O}_{4}(25,65)$.

$\mathrm{Fe}_{3} \mathrm{O}_{4}$ appears to be widely distributed in the biological world (48) in addition to its presence in pigeons and honey bees. Magnetic inclusions have been reported in organisms as diverse as dolphins (76), butterflies (33), tuna (71), green turtles (56), marine crustacea (16), bacteria (24), and humans 14.43). The first identification of $\mathrm{Fe}_{3} \mathrm{O}_{4}$ in an organism was by Lowenstam 
(47), who found it in the tooth denticles on the radulac of a group of mollusks called chitons. $\mathrm{Fe}_{3} \mathrm{O}_{4}$ is very hard as well as magnetic, making it useful as tooth mineral for chitons, which scrape algac off rocks. This illustrates the fact that the presence of $\mathrm{Fe}_{3} \mathrm{O}_{4}$ does not necessarily mean that the organism has a magnetic detector. In addition to being magnetic and hard, $\mathrm{Fe}_{3} \mathrm{O}_{4}$ is apparently one of the densest materials that can be mineralized by living organisms. This property might also play a role in certain cases.

\section{MAGNETOTACTIC BACTERIA}

The best documention to date for the connection between magnetically sensitive behavior and the presence of $\mathrm{Fe}_{3} \mathrm{O}_{4}$ is in aquatic bacteria that orient and swim along magnetic field lines (7-9). This behavior is termed magnetotaxis. Magnetotactic bacteria were discovered serendipitously in the early 1970 s by Blakemore (7), who found bacteria, from both freshwater and marine muds, that accumulated at the North side of drops of water placed on a microscope slide. These bacteria swam toward and away from the south pole and north pole of a bar magnet, respectively. ' Subsequently, Kalmijn \& Blakemore (38) used homogeneous magnetic fields produced by Helmholtz coils to show that New England bacteria swim along magnetic field lines in the field direction, that is, in the direction indicated by the North-seeking pole of a magnetic compass needle. When the field produced by the coils is reversed by reversing the direction of current flow, the bacteria respond immediately by executing "U-turns" and continuing to swim in the field direction. Killed cells orient along the field lines and totate when the field direction is reversed, but they do not move along the field lines. Thus, magnetotactic bacteria from New England behave as selfpropelled magnetic dipoles and are predominantly North-seeking $(38,53)$.

\section{Magnetosomes}

Magnetotactic bacteria are found in the sediments of many aquatic environments $(8,20,23,53)$. In addition to their worldwide distribution, the diversity of morphological types suggests that magnetotaxis is a feature of a number of bacterial species. Two characteristics unify these species. Apparently, they are all anaerobic or microaerophilic (8) and they all contain magnetosomes (5), which are unique intracytoplasmic structures consisting of membrane-bounded magnetite $\left(\mathrm{Fe}_{3} \mathrm{O}_{4}\right)(24,52,66)$ (Figure 1). One species, Aquaspirillum magnetotacticum, has been isolated and grown

\footnotetext{
1 A bacterium that swims toward the south pole of a bar magnet will swim Northward in the geomagnetic field.
} 


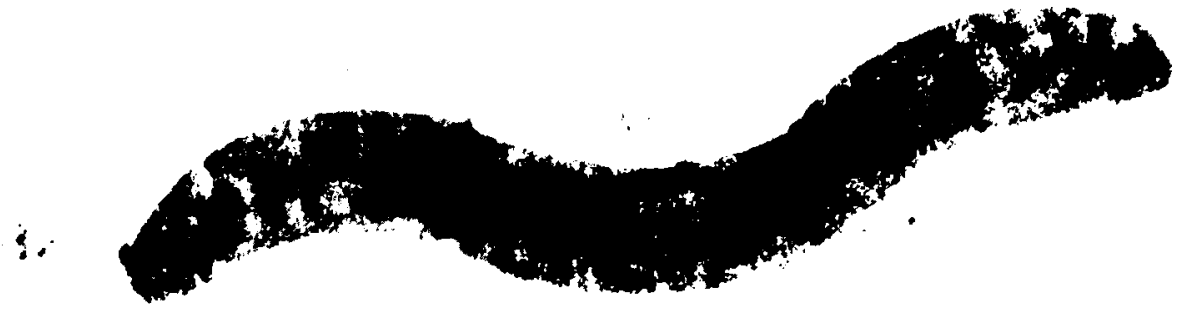

Figure 1 Electron micrograph of a magnetotactic spirillum. The chain of electron-opaque particles are the magnetosomes, the enveloped $500-\mathrm{A}$ particles of $\mathrm{Fe}_{3} \mathrm{O}_{4}$. The cell length is approximately $3 \mu \mathrm{m}$.

in pure culture in a chemically defined medium (11). Iron accounts for $2 \%$ of the dry weight of this species. Most of the iron (80-90\%) is present in the form of the cytoplasmic membrane-bounded, 40-50-nm wide particles of $\mathrm{Fe}_{3} \mathrm{O}_{4}$ (24) (Figure 2). Cells also contain ferrous iron and hydrous-ferric-oxide (ferrihydrite) (25) (Figure 3). The enveloped $\mathrm{Fe}_{3} \mathrm{O}_{4}$ particles (magnetosomes) are arranged in a chain that longitudinally traverses the cell (Figure 1) in close proximity to the inner surface of the cytoplasmic membrane (5). The number of magnetosomes in the chain is variable, depending upon the culture conditions, but typically averages 20 . Magnetosomes are enveloped by electron-transparent and electron-dense layers, and each is separated from those adjacent to it by $10-\mathrm{nm}$ regions containing cytoplasmic material free of ribosomes or other particulate elements (5). The chemical composition of the distinctive region surrounding the bacterial magnetite grains is unknown but may be important in their formation. Magnetite particles extracted from cells by brief sonication retain an envelope, although their interparticle separation is less than $50 \%$ of that separating particles in chains within intact cells (5). Magnetosomes containing $\mathrm{Fe}_{3} \mathrm{O}_{4}$ have been identified in several other bacterial species as well $(52,66)$. In two cases, high resolution electron microscopy has shown that the $\mathrm{Fe}_{3} \mathrm{O}_{4}$ particles are single crystals $(52 ; \mathrm{S}$. Mann and R. J. P. Williams, unpublished information). 


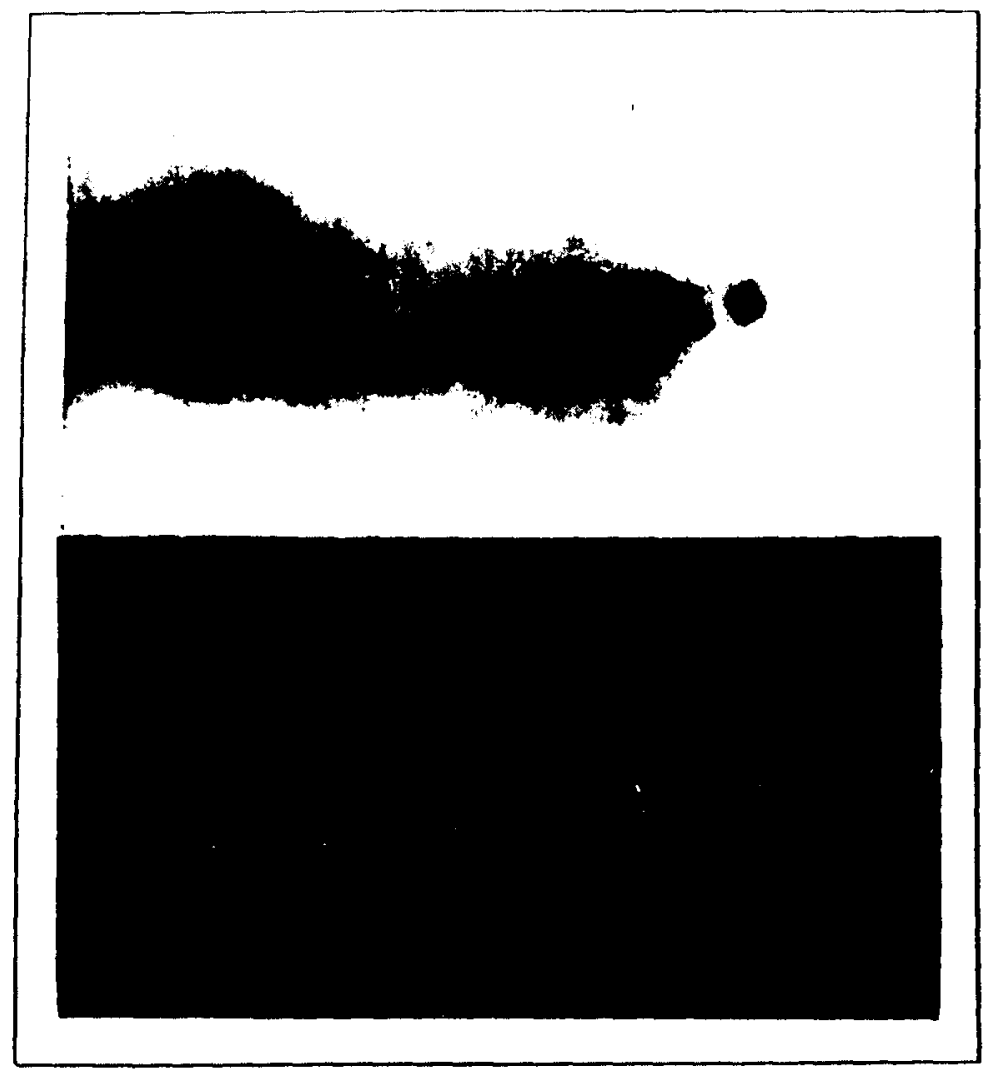

Figure 2 Transmission electron micrograph of A. magnetotacticum (top) and iron X-ray pulse map (bortom) showing that iron in the cell is localized in the magnetosomes [after (25)].

\section{Mechanism of Magnetotaxis}

The magnetosome chain in A. magnetotacticum imparts a magnetic dipole moment to the cell, parallel to the axis of motility, sufficient to orient the cell in the geomagnetic field (22). First, consider the size of the $\mathrm{Fe}_{3} \mathrm{O}_{4}$ particles. Large particles of $\mathrm{Fe}_{3} \mathrm{O}_{4}$ form magnetic domains that reduce the remanent magnetic moment and hence the magnetostatic energy. The domains are separated by transition regions or domain walls. When the particle length $d$ is less than the width of a domain wall, it cannot form domains and will be a single magnetic domain. The upper limit for single magnetic domains $d_{s \mathrm{~d}}$ is thus approximately the width of a domain wall $d_{w}$, which is a function of the exchange and anisotropy energy of the material

$$
d_{\mathrm{w}}=\left(\frac{k T_{\mathrm{c}}}{K a^{3}}\right)^{1 / 2} a
$$




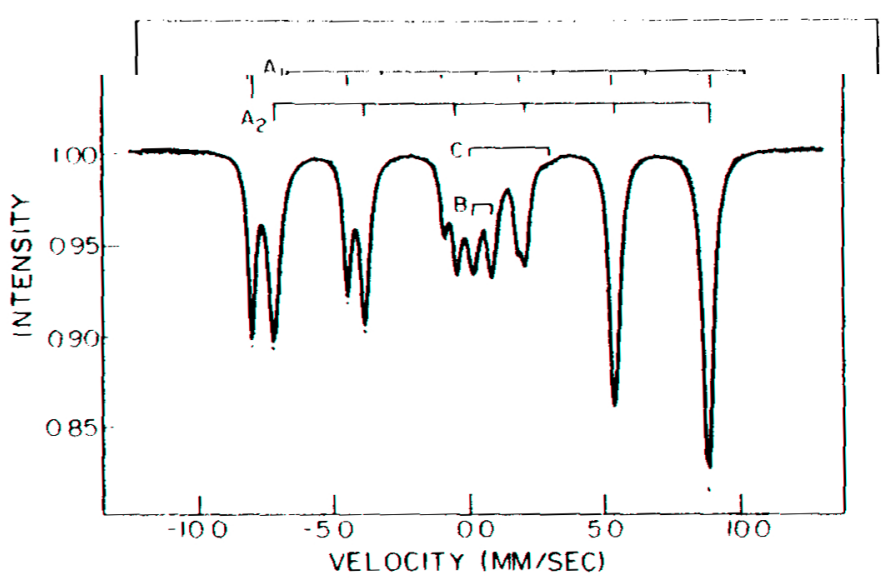

Fiqure 3 Mössbauer spectrum of frozen cells of $A$. magnetotacticum. Subspectra $A_{1}$ and $A_{2}$ are due to $\mathrm{Fe}_{3} \mathrm{O}_{4}$. Subspectrum $\mathrm{B}$ is a ferric doublet; subspectrum $\mathrm{C}$ is a ferrous doublet [after (25)]. The ferric and ferrous materials are precursors to $\mathrm{Fe}_{3} \mathrm{O}_{4}$ precipitation.

where $k$ is Boltzmann's constant, $T_{c}$ the Curie temperature, $K$ the anisotropy energy, and $a$ the atomic spacing. Substituting values for $\mathrm{Fe}_{3} \mathrm{O}_{4}$ (54) yields $d_{w}=500 \AA$. More precise calculations by Butler \& Banerjee (17) for equidimensional particles yield $d_{s d}=760 \AA . d_{\text {sd }}$ increases with the axial ratio (length/width). On the other hand, if the particle dimension is less than a certain value $d_{s}$, it will be superparamagnetic at room temperature ; that is, thermal energy will cause transitions of the single domain magnetic moment between equivalent easy magnetic axes of the particle with a consequent loss of the time-averaged remanent moment (6). The transition frequency $f$ is a function of the anisotropy energy, volume, and the thermal energy:

$$
f \sim f_{0} \exp \left[\frac{-K V}{2 k T}\right]
$$

where $f_{0}$ is a constant of the order of $10^{9} \mathrm{~s}^{-1}$ and $V\left(=d^{3}\right)$ is the particle volume. Particles of dimensions greater than $350 \AA$ are stable for times greater than $10^{6}$ years; hence $d_{s}<350 \AA$. Thus, particles of $\mathrm{Fe}_{3} \mathrm{O}_{4}$ with dimensions $350 \AA<d<760 \AA$ are permanent, single magnetic domains with remanent moments of $480 \mathrm{G} / \mathrm{cm}^{3}$. So we can assume that each $500-\AA$ particle produced by a bacterium has a magnetic moment of $6.0 \times 10^{-14}$ emu.

Second, consider the chain structure. When the single domain particles are organized in a chain as they are in $A$. magnetotacticum, the interactions 
between the particle moments will cause them to be oriented parallel to each other along the chain direction (32). Thus, the moment of the entire chain will be equal to the sum of the individual particle moments. For chains of twenty-two particles, this gives a total remanent moment $M=1.3 \times 10^{12} \mathrm{emu}$. Since the particles are fixed in the bacterium by the magnetosome envelope, the bacterium is, in effect, a swimming magnetic dipole.

The simplest hypothesis for magnetotaxis is passive orientation of the swimming bacterium along the magnetic field lines by the torque exerted by the field on the magnetic moment (22). Thermal energy, on the other hand, will tend to disorient the bacterium during swimming. In a magnetic field $\mathbf{B}$, the energy of the bacterial moment

$$
\begin{aligned}
E_{\mathrm{m}} & =-\mathbf{M} \cdot \mathbf{B} \\
& =-M B \cos \theta,
\end{aligned}
$$

where $\theta$ is the angle between $\mathbf{M}$ and $\mathbf{B}$. The thermally averaged orientation of an ensemble of moments, or equivalently, the time averaged orientation of a single moment

$$
\langle\cos \theta\rangle=\frac{\int \cos \theta e^{-E_{\mathrm{m}} / k T} d V}{\int e^{-E_{\mathrm{m}} / d t} d V}=L(\alpha) .
$$

$L(\alpha)$ is the Langevin function,

$$
L(\alpha)=\operatorname{coth}(\alpha)-\frac{1}{\alpha} ; \quad \alpha=M B / k T,
$$

and is plotted in Figure 4. If we consider A. magnetotacticum in the earth's magnetic field of $0.5 \mathrm{G}$ at room temperature, then $\alpha \sim 16$ and $\langle\cos \theta\rangle$ $>0.9$. Because the Langevin function asymptotically approaches one as $\alpha$ increases, the orientation would not improve significantly if there were more particles and the moment per bacterium were larger. Thus each bacterium is in effect a biomagnetic compass optimized to the geomagnetic field at room temperature.

For passively oriented bacteria, the migration velocity along the magnetic field lines

$$
v_{\mathrm{B}}=v_{0}\langle\cos \theta\rangle \text {, }
$$

where $v_{0}$ is the forward velocity of the swimming bacterium and $\theta$ is the angle between the axis of motility and the magnetic field. If $v_{0}$ is independent of $B$ and the magnetic moment is parallel to the axis of 


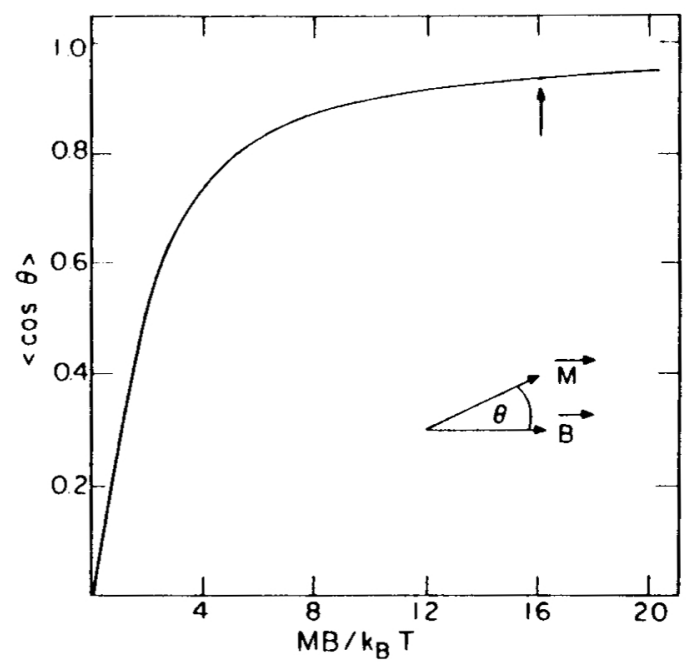

Figure 4 Langevin function plotted against $M B / k T$. The vertical arrow indicates the average orientation of bacteria with moments $M=1.3 \times 10^{-12} \mathrm{emu}$ in an $0.5-\mathrm{G}$ field at $300 \mathrm{~K}$.

motility,

$$
v_{\mathrm{B}}=v_{0} L(\alpha) \text {, }
$$

providing that the velocity is averaged over a time that is long compared to the rotational diffusion time

$$
\tau=\frac{8 \pi r^{3} \eta}{k T} \simeq 1 \mathrm{~s}
$$

where $r$, the effective hydrodynamic radius of bacterium $=0.5 \mu \mathrm{m}$, and the viscosity of water $=0.01$ poise. Equation 7 is the basis of a method for measuring the magnetic moments of individual bacteria (36).

For bacteria with moments $>10^{-12} \mathrm{emu}$, the migration speed along magnetic field lines is thus $>90 \%$ of their forward speed. This is in contrast to the relatively slow migration of chemotactic bacteria that vary the duration of swimming according to the orientation of the chemical concentration gradient.

The width of a "U-turn" executed by a bacterium following an instantaneous field reversal can also be calculated (C. P. Bean, private communication). In the world of the bacterium, inertial effects are negligible 159). and hence the torque exerted on the moment by the field is proportional to angular velocity:

$$
\mathbf{M} \times \mathbf{B}=M I B \sin \theta=8 \pi r^{3} \eta \frac{d \theta}{d t} .
$$


We deline

$$
\tau_{0}=\frac{8 \pi r^{3} \eta}{M B}
$$

then the velocity perpendicular to the field

$$
\begin{aligned}
v_{1} & =v_{0} \sin \theta \\
& =v_{0} \tau_{0} \frac{d \theta}{d t} .
\end{aligned}
$$

The width of the "U-turn"

$$
\begin{aligned}
W & =\int v_{\perp} d t \\
& =v_{0} \tau_{0} \pi .
\end{aligned}
$$

From the definition of $\tau_{0}, W$ is inversely proportional to $M B$ and a measurement of $W$ can in principle yield $M$. An actual measurement, however, would be experimentally complicated by the requirement that the bacterium confines itself to a horizontal plane during the "U-turn." The method has been applied to microorganisms from Rio de Janeiro (20). An unidentified coccus with $6-\mu \mathrm{m}$ diameter had a magnetic moment of $4.7 \times 10^{-12} \mathrm{emu}$.

The average magnetic moment per cell of bacteria in culture has been determined by elastic light scattering (62) and magnetically induced birefringence (61). The latter method depends on the anisotropic optical polarizability of the bacteria, which results in a net birefringence $\Delta \boldsymbol{n}$ in the sample when the bacteria are oriented by an applied magnetic field. The orientation is axial, not polar, and is proportional to the ensemble average of the second Legendre polynomial

$\Delta n \propto\left\langle P_{2}(\cos \phi)\right\rangle$.

The angular distribution function of the bacteria about the field direction is given by

$$
f(\phi, \alpha)=\frac{\alpha \exp [\alpha \cos \phi] \sin \phi}{\alpha \sinh \alpha} ;
$$

hence

$$
\begin{aligned}
\left\langle P_{2}(\cos \phi)\right\rangle & =\int P_{2}(\cos \phi) f(\phi, \alpha) d \phi \\
& =1-\frac{3 \operatorname{coth} \alpha}{\alpha}+\frac{3}{\alpha^{2}} .
\end{aligned}
$$


Measurements of $\Delta n$ as a function of $B$ can be fitted with Equation 15 to yield the average moment (61). Bacteria cultured under particular conditions had an average magnetic moment of $10^{13} \mathrm{emu}$.

Aquaspirillum magnetotacticum is bipolarly fagellated, that is, it has a flagellum at each end of the cell and can swim in either direction along the magnetic field lines. However, most other magnetotactic bacterial species in sediments are asymmetrically flagellated and have unidirectional motility. As noted above, these bacteria from New England swim along magnetic field lines in the field direction. Based on the passive orientation hypothesis, this occurs if the bacterial moment is oriented in the cell forward with respect to the flagellum (Figure 5). Then the bacterium will propel itself in the field direction when the moment is oriented in the field, and will be North-seeking in the geomagnetic field. If the bacterial moment were oriented in the cell rearward with respect to the flagellum, the cell would propel itself opposite to the field direction when the moment was oriented in the field, and hence would be South-seeking in the geomagnetic field.

South-seeking bacteria have been produced in the laboratory by subjecting North-seeking cells to magnetic pulses (38) or ac magnetic fields (10) that are strong enough to overcome the magnetic interaction forces between the particles in the chain and cause their moments to rotate and reorient along the chain the opposite direction. Pulse strengths of several hundred gauss are required, consistent with magnetic measurements on freeze-dried cells (19) and in agreement with estimates based on the "chain of spheres" model of Jacobs \& Bean (32), who considered the magnetic properties of a chain of single domain particles in a different context before the discovery of magnetotactic bacteria.

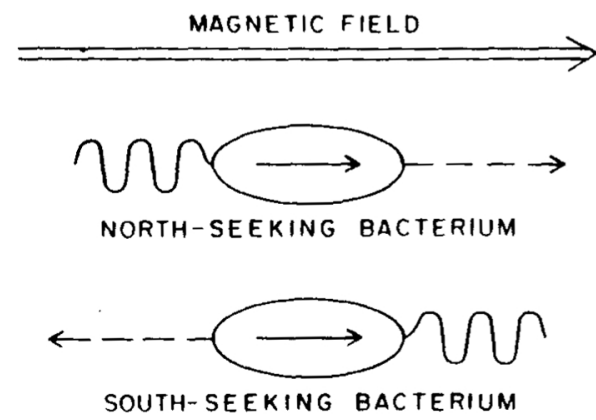

Figure 5 Illustration of North-seeking and South-seeking bacleria in a magnetic field. The solid arrows indicate the magnetic dipole moments of the cells that are due to the $\mathrm{Fe}_{3} \mathrm{O}_{4}$ particles. The arrowhead is the North-seeking pole. When the North-seeking pole is forward with respect to the flagellum, the bacterium will migrate in the field direction. or Northward in the geomagnetic field, i.e. the cell is North-seeking. If the South-seeking pole is forward, the hacterium will migrate opposite to the field direction, or Southward in the geomagnetic field, ic the cell is South-seeking. 


\section{Biological Advantage}

The predominance of North-seeking bacteria in the Northern Hemisphere is due to the inclination of the geomagnetic field $(8,9)$. Since many sedimentdwelling bacteria are anaerobic or microaerophilic, it is advantageous for them to have mechanisms that prevent them from swimming up toward the toxic, higher oxygen concentration at the water surface and that keep them in the sediments. Since the geomagnetic field is approximately dipolar, the magnetic field lines at the earth's surface are inclined at an angle that increases with latitude. The total flux density at latitude $\theta$ is approximately

$$
B_{G}=0.3\left(\sin ^{2} \theta+1\right)^{1 / 2} G \text {, }
$$

and the inclination $I$ of the field from the horizontal is given by

$$
\tan I=2 \tan \theta .
$$

In the Northern Hemisphere the field is inclined downwards, pointing straight down at the North magnetic pole. In the Southern Hemisphere the field is inclined upwards, at an angle increasing with latitude, pointing straight up at the South magnetic pole. At the geomagnetic equator the field is horizontal.

Because of the inclination of the field lines, North-seeking bacteria migrate downward in the Northern Hemisphere and upward in the Southern Hemisphere (Figure 6). South-seeking bacteria migrate upward in the Northern Hemisphere and downward in the Southern Hemisphere. At the equator, both polarity types migrate horizontally. Because downward directed motion is advantageous, North-seeking bacteria should be favored

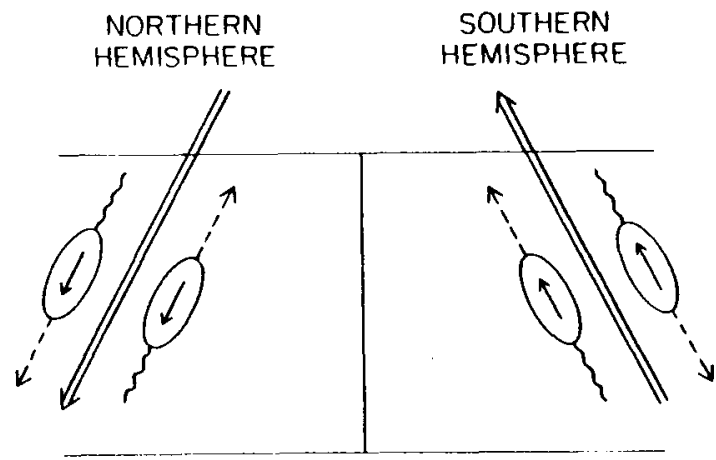

Figure 6 Because of the inclination of the geomagnetic field, North-seeking and Southseeking bacteria migrate downward and upward, respectively, in the Northern Hemisphere and upward and downward, respectively, in the Southern Hemisphere. At the geomagnetic equator, both polarities migrate horizontally. 
in the Northern Hemisphere and South-seeking bacteria should be favored in the Southern Hemisphere. At the equator neither polarity would be favored.

Examination of bacteria in sediments from various places in the world confirms this hypothesis. In contrast to New England (inclination $70^{\prime} \mathrm{N}$ ) and other Northern Hemisphere locales, magnetotactic bacteria in freshwater and marine sediments in Australia and New Zealand (inclination $70^{\prime} \mathrm{S}$ ) are almost exclusively South-seeking $(10,41)$, as are bacteria in Rio de Janerio (inclination $\left.25^{\circ} \mathrm{S}\right)(20,23)$. These bacteria have chains of particles and can be remagnetized to North-seeking polarity (10). At the geomagnetic equator in Brazil (inclination $0^{\circ}$ ) both North-seeking and Southseeking bacteria are present in roughly equal numbers (23). Thus the vertical component of the geomagnetic field selects the predominant cell polarity in natural environments, with downward directed motion advantageous for, and upward directed motion detrimental to, survival of the organisms. At the geomagnetic equator where motion is directed horizontally, both polarities benefit because horizontally directed motion presumably reduces harmful upward migration. Examination of sediments on the coast of Brazil just South of the geomagnetic equator shows that Southseeking bacteria predominate when the magnetic inclination is greater than about $8^{\circ}$ (F. F. Torres de Araujo et al, unpublished information).

The role of the vertical magnetic field component has also been confirmed in laboratory experiments $(10,23)$. When a sediment sample from New England, initially containing North-seeking bacteria, was placed in a coil that produced a field of twice the magnitude and opposite sign to the ambient vertical field, the polarity of the bacteria in the sample inverted over several weeks, that is over many bacterial generations. In a sample placed in a coil that canceled the vertical component of the ambient magnetic field, the population in the sample tended toward equal numbers of both polarities, again over many generations. Equal numbers of both polarities also resulted when samples initially containing all North-or all South-seeking bacteria were placed in an enclosure that canceled the ambient magnetic field. Further experiments in null field by Blakemore (8) confirmed the role of oxygen. When samples with tight stoppers were placed in the zero field enclosure, bacteria of both polarities were ultimately found in the sediment and in the water column up to the surface. When the sample bottles were loosely stoppered, allowing diffusion of air, bacteria were found in the sediments but not in the water column.

While the ability to synthesize $\mathrm{Fe}_{3} \mathrm{O}_{4}$ and construct magnetosomes is ccrtainly genetically encoded, the polarity of the magnetosome chain cannot be encoded. If a bacterium that lacks magnetosomes starts to synthesize them de novo, there is equal probability that when the particles 
grow to permanent single domain size, the chain will magnetize with Northsecking pole forward as with South-seeking pole forward; a population of these bacteria will consist of 1:1 North-seckers and South-seekers. If however, the daughter cells inherit some of the parental magnetosomes during cell division, they will inherit the parental polarity. As they synthesize new magnetosomes at the ends of their inherited chains, the magnetic field produced by the existing particles will magnetize the new particles in the same orientation. Thus, North-seeking bacteria can produce Norlh-seeking progeny and South-seeking bacteria can produce Southseeking progeny. This has been cited as a rudimentary example of "geneculture transmission" (C. J. Lumsden, to be published). However, there are mechanisms by which some progeny with the opposite polarity can be produced in each generation (21). For example, if in the cell division process some of the daughter cells inherit no parental magnetosomes, these cells will synthesize them de novo and about one half those cells will end up with the polarity opposite to that of the parental generation. So in New England where North-seeking bacteria are found and predominate, some Southseekers are produced in each population division. Under normal circumstances, these South-seekers are unfavored by being directed upwards towards the surface, when they are separated from the sediments, and their total population remains low compared to the North-seeking population. However, when the vertical magnetic field is inverted, as in the experiment described above, these South-seekers are suddenly favored and their progeny eventually predominate as the previously favored North-seeking population declines in their newly unfavorable circumstances. When the vertical component is set equal to zero, neither polarity is favored and the North-seeking and South-seeking populations eventually equalize.

We can envision a similar process occurring in natural environments during reversals or excursions of the geomagnetic field. During these processes the vertical component changes sign over thousands of years. This would be accompanied by a change in the predominant polarity of the magnetotactic bacterial population in that locale. Models for the equilibrium polarity ratio as a function of geomagnetic field inclination have been proposed ( $N$. Germano et al, unpublished information). In these models, even a small differential survival probability strongly favors one polarity over the other. This is consistent with the observation that in natural environments a geomagnetic inclination of $8^{\circ}$ is sufficient to select one polarity (F. F. Torres de Araujo et al unpublished information).

Other possible advantages of rapid straight-line motion to magnetotactic bacteria might include population dispersal, escape, and outrunning chemical diffusion. There are also consequences of magnetotaxis and 
$\mathrm{Fe}_{3} \mathrm{O}_{4}$ synthesis that may or may not be advantageous. Magnetic bacteria that are within $4 \mu \mathrm{m}$ of each other will experience magnetic forces greater than the forces of Brownian motion. $\mathrm{Fe}_{3} \mathrm{O}_{4}$ synthesis also increases the density of the bacteria, helping them to stay down in the sediments even when they are not swimming, and may serve some metabolic functions as well (8).

The high density of $\mathrm{Fe}_{3} \mathrm{O}_{4}\left(\rho=5.1 \mathrm{gms} / \mathrm{cm}^{3}\right)$ could conceivably play a role in geotaxis, whereby microorganisms would be oriented in the gravitational field so that they could swim upward or downward ( $E$. Purcell, private communication). Imagine a cylindrical bacterium of length $2 l=4 \mu \mathrm{m}$ with a segment of $\mathrm{Fe}_{3} \mathrm{O}_{4}$ at one end. When suspended in water this hypothetical bacterium would tend to orient with the $\mathrm{Fe}_{3} \mathrm{O}_{4}$ segment downward. If the flagellum were opposite the $\mathrm{Fe}_{3} \mathrm{O}_{4}$ segment, the bacterium would migrate downward. The mass of $\mathrm{Fe}_{3} \mathrm{O}_{4}$ required can be estimated as follows. The orientational energy of the bacterium in the gravitational field

$$
E_{\mathrm{g}}=-V\left(\rho-\rho_{0}\right) \lg \cos \theta
$$

where $V$ is the volume and $\rho$ is the density of the $\mathrm{Fe}_{3} \mathrm{O}_{4}$ segment, $\rho_{0}$ is the density of water, $l$ is one half the length of the cell (approximately the distance between the center of the cell and the center of the $\mathrm{Fe}_{3} \mathrm{O}_{4}$ segment), $g$ is the acceleration due to gravity and $\theta$ is the angle between the bacterium and the vertical direction. We assume that the density of the bacterium exclusive of the $\mathrm{Fe}_{3} \mathrm{O}_{4}$ segment is the same as water. Then the thermally averaged orientation

$$
\langle\cos \theta\rangle=L(\beta)=\operatorname{coth}(\beta)-\frac{1}{\beta},
$$

where $L(\beta)$ is the Langevin function and

$$
\beta=V\left(\rho-\rho_{0}\right) \lg / k T \text {. }
$$

Arbitrarily defining "good" average orientation as $\langle\cos \theta\rangle \geq 0.8$, means $\beta \geq 10$. With $\rho-\rho_{0}=4.1, T=300 \mathrm{~K}$, and $l=2 \mu \mathrm{m}$, this requires $V \sim 5 \times 10^{-13} \mathrm{~cm}^{3}$, or $2.5 \times 10^{-12} \mathrm{~g}$ of $\mathrm{Fe}_{3} \mathrm{O}_{4}$. A smaller value of $l$ would require an even larger mass of $\mathrm{Fe}_{3} \mathrm{O}_{4}$. For comparison, A. magnetotacticum lypically contains $1.25 \times 10^{-14} \mathrm{~g}$ of $\mathrm{Fe}_{3} \mathrm{O}_{4}$, which is sufficient for orientation ( $\langle\cos \theta\rangle \geq 0.9$ ) in the geomagnetic field. Hence in A. magnetotacficum neither is there enough $\mathrm{Fe}_{3} \mathrm{O}_{4}$, nor is the $\mathrm{Fe}_{3} \mathrm{O}_{4}$ present in the cell appropriately distributed to function in geotaxis. This calculation illustrates that $\mathrm{Fe}_{3} \mathrm{O}_{4}$ is typically five hundred time more efficient for magnetotaxis than for geotaxis in microorganisms. 


\section{Biomineralization of $\mathrm{Fe}_{3} \mathrm{O}_{4}$}

Progress has been made in elucidating the $\mathrm{Fe}_{3} \mathrm{O}_{4}$ biomineralization process. On the basis of extensive Mössbauer spectroscopic analysis, it has been proposed that $A$. magnetotacticum precipitates $\mathrm{Fe}_{3} \mathrm{O}_{4}$ in the sequence $\mathrm{Fe}^{3+}$ quinate $\rightarrow \mathrm{Fe}^{2+} \rightarrow$ low density hydrous ferric oxide $\rightarrow$ high density hydrous ferric oxide (ferrihydrite) $\rightarrow \mathrm{Fe}_{3} \mathrm{O}_{4}$ (25). In nonmagnetic variants the process stops with high density hydrous ferric oxide (ferrihydrite) or with low density hydrous ferric oxide. In the proposed process, iron enters the cell as $\mathrm{Fe}^{3+}$ chelated by quinic acid. Reduction to $\mathrm{Fe}^{2+}$ releases iron from the chelator. $\mathrm{Fe}^{2+}$ is reoxidized and accumulated as the low density hydrous iron oxide. By analogy with the deposition of iron in the micellar cores of the protein ferritin (18), this oxidation step might involve molecular oxygen. which is required for $\mathrm{Fe}_{3} \mathrm{O}_{4}$ precipitation in $A$. magnetotacticum (D. Bazylinski and R. P. Blakemore, unpublished information). Dehydration of the low density hydrous ferric oxide results in ferrihydrite. Finally, partial reduction of ferrihydrite and further dehydration yields $\mathrm{Fe}_{3} \mathrm{O}_{4}$.

Mössbauer spectroscopy measurements of whole cells above freezing temperatures show that diffusive motions of the $\mathrm{Fe}_{3} \mathrm{O}_{4}$ particles are small, that is, the particles are effectively fixed in the cell. The ferrihydrite is associated with the magnetosome chain, but $\mathrm{Fe}^{2+}$ is located elsewhere in the cell, possibly in the cell wall (S. Ofer et al, to be published).

$\mathrm{Fe}_{3} \mathrm{O}_{4}$ is thermodynamically stable with respéct to hematite and ferrihydrite at low $E_{\mathrm{H}}$ and high $\mathrm{pH}(26)$. It is known that magnetite can be precipitated by the controlled addition of $\mathrm{O}_{2}$ to mixed ferrous and ferric hydroxides (green rust) (49) or by the addition of $\mathrm{Fe}^{2+}$ ions to lepidocrocite $(\gamma-\mathrm{FeOOH})(64)$. The latter process is a surface reaction involving dissolution of the $\gamma-\mathrm{FeOOH}$ and reprecipitation of $\mathrm{Fe}_{3} \mathrm{O}_{4}$. Lepidocrocite has not been detected in $A$. magnetotacticum, but a similar reaction might occur with ferrihydrite, especially on poorly crystallized or amorphous particles. In any case, the fact that the precipitation process requires control of the size and location of the $\mathrm{Fe}_{3} \mathrm{O}_{4}$ as well as probable spatial segregation of regions of differing $E_{\mathrm{H}}$ and possibly $\mathrm{pH}$ in the cell suggests that the precipitation process is "matrix mediated" $(48,72)$. The magnetosome envelope is probably an integral element in the precipitation process and may function as a locus for enzymatic activities, including control of $E_{\mathrm{H}}$ and $\mathrm{pH}$, as well as a structural element.

Reduction of a ferrihydrite precursor to $\mathrm{Fe}_{3} \mathrm{O}_{4}$ also occurs in the marine chiton, a mollusk of the genus Polyplacophora (65). In this organism the radular teeth undergo a sequential mineralization process that results in a surface coating of $\mathrm{Fe}_{3} \mathrm{O}_{4}$. Iron is transported to the superior epithelial cells 
of the radula as ferritin. Then iron is transferred to a preformed organic matrix on the tooth surface as ferrihydrite. Finally, the ferrihydrite is reduced to $\mathrm{Fe}_{3} \mathrm{O}_{4}$. Thus the $\mathrm{Fe}_{3} \mathrm{O}_{4}$ precipitation processes in chitons and in magnetotactic bacteria appear to be similar.

\section{CONCLUSION}

In conclusion, magnetotactic bacteria precipitate $\mathrm{Fe}_{3} \mathrm{O}_{4}$. The precipitation process is controlled to produce the magnetosome chain, a highly structured magnetic element in the cell that results in the migration of the bacterium along geomagnetic field lines. The vertical component of the geomagnetic field is the important element in determining the predominant polarity of bacteria in natural environments, with downward directed motion favored over upward directed motion. Downward directed motion guides the bacteria to, and keeps them in, their preferred habitat, the relatively anoxic sediments. In fact, the low $\mathrm{O}_{2}$ environment appears to be a requirement for $\mathrm{Fe}_{3} \mathrm{O}_{4}$ precipitation.

The fact that the magnetic sensitivity of magnetotactic bacteria is based on $\mathrm{Fe}_{3} \mathrm{O}_{4}$ suggests that the magnetic sensitivity of some complex organisms could also be connected with $\mathrm{Fe}_{3} \mathrm{O}_{4}$ precipitates. Of course, the passive orientation mechanism is suitable only for motile microorganisms. In larger organisms $\mathrm{Fe}_{3} \mathrm{O}_{4}$ would be part of a sensory system. The detailed anatomical and physiological description of such systems remains for future research.

\section{ACKNOWLEDGMENTS}

I gratefully acknowledge the continued collaboration of Richard Blakemore in the study of magnetotactic bacteria. I am also grateful to many colleagues and friends for contributions and discussions. G. Lynch provided editorial assistance. This work was partially supported by the Office of Naval Research. The Francis Bitter National Magnet Laboratory is supported by the National Science Foundation.

\section{Literafure Cited}

1. Able, K. P. 1980. In Animal Migration, Orientation and Navigation, ed. S. A. Gauthreaux, pp. 283-373. New York: Academic

2. Baker, R. R. 1980. Science $210: 555-57$

3. Hiker, R. R. 1981 . Human Navigation and the Sirth Sense. London: Hodder \& Stoughton. $310 \mathrm{pp}$.

4. Hiker, R. R., Mather, J.G., Kennaugh, J II. 1983. Nature 301:78-80

s Malk will. D. L.. Maratea, D.. Blakemore,
R. P. 1980. J. Bacteriol. $141: 1399-1408$

6. Bean, C. P., Livingston, J. D. 1959. J. Appl. Phys. 30:120S-29S

7. Blakemore. R. P. 1975. Science $190: 377$ 79

8. Blakemore, R. P. 1982. Ann. Rev. Microbiol. $36: 217-38$

9. Blakemore, R. P., Frankel, R. B. 1981. Sci. Am. 245(6) : 58-65

10. Blakemore, R. P., Frankel, R. B. Kalmijn, A. J. 1981. Nature 286:384-85 
II. Blakemore, R. P., Maralea, D., Wolle, R. S. 1979. J. Bacleriol. 140:720 29

12. Bookman. M. A. 1977. Nalure 267:34042

13. Brown, F. A. Jr., Barnwell, J. Il., Webh, II. M. 1964. Biol Bull. 127:221 31

14. Brown, F. A. Ir. Park, Y. II. 1965. Biol. Bull. 128: 347 55

15. Brown, H. R., Ilyinsky, O. B., Muravejko, V. M.. Corshkov. E. S., Fonarev, G. A. 1979. Nature 277:648 49

16. Buskirk, R. E. 1981. Trans. Am. Geophys. Union $62: 850$

17. Butler, R. F., Banerjee, S. K. 1975. J. Geophys. Res. 80:4049-58

18. Clegg, G. A., Fitton, J. E., Harrison, P. M. Treffry, A. 1980. Mol. Biol. 36:56-80

19. Denham, C. R., Blakemore, R. P., Frankel. R. B. 1980. IEEE Trans. Magn. MACi-16:1006 7

20. Esquivel, D. M. S., Lins de Barros, H. G. P., Farina. M., Aragao, P. H. A., Danon, J. 1983 Biol. Cell $47: 227-34$

21. Frankel. R. B. 1982 . Comments $\mathrm{Mol}$. Cell. Biophys. 1:293-310

22. Frankel, R. B., Blakemore, R. P. 1980. J. Magn. Maan. Mater. 15-18:1562-44

2.3. Frankel, R. B., Blakemore, R. P., Torres de Araujo, F. F., Esquivel, D. M. S., Danon, J. 1981. Science 212: 1269-70

24. Frankel, R. B., Blakemore, R. P., Wolfe, R. S. 1979. Science 203: 1355-56

25. Frankel, R. B., Papaefthymiou, G. C., Blakemore, R. P., O'Brien, W. D. 1983. Biochim. Biophys. Acta 763:147-59

26. Garrels, R. M., Christ, C. L. 1965. Solution, Minerals and Equilibria. New York: Harper \& Row. 450 pp.

27. Gilbert, W. 1600. De Magnete Magneticisque Corporibus et de Magne Magnete Tellure. London: Petrus Short. $240 \mathrm{pp}$.

28. Gould, J. L. 1980. Am. Sci. 68:256-67

29. Gould, J. L 1981. Nature 296:205-1 I

30. Gould, J. L., Able, K. P. 1981. Science $212: 106163$

31. Gould, J. L., Kirschvink, J. L., Defleyes, K. S. 1978. Science 201: 1026-28

32. Jacobs, I. S., Bean, C. P. 1955. Phys. Rev. $100: 1060-67$

33. Jones, D. S., MacFadden, B. J. 1982. $J$. Exp. Biol. 96:1-9

34. Jungerman, R. L.. Rosenblum, B. 1980.J. Theor. Biol. $87: 25-32$

35. Kalmijn, A. J. 1974. In IIandbook of Sensory Physiology, ed. A. Fessard, 3(3): 147-200. Berlin : Springer-Verlag

36. Kalmijn, A. J. 1981. IEEE Trans. Magn. MAG-17:1113-23

37. Kalmijn, A. J. 1982. Science 218:916-18

38. Kalmijn. A. J., Blakemore, R. P. 1978. In Animal Migration, Navigation and Ilominy, ed. K. Schmidt-Koenig, W. T. Keeton, pp. 354-55. New York:
Springer-Verlatg

39. Kecton, W. T. 1971. Pros. Nall. Acad Sci. USA 68: 1026

40. Keeton, W. T., larkin, T.S., Windsor, D. M. 1974. J. Comp. Phisiol.95:95 103

41. Kirschvink, J. 1. 1980. J. Exp. Biol. 86: 345-47

42. Kirschvink, J. I. 1981. Biosistems 14 : 193.203

43. Kirschvink, J. L. 1981 J. Exp. Biol. 92 : 333-35

44. Kirschvink, J. L., Gould, J. L. 1981. Biosystemis 13:181 -201

45. Kuterbach, D. A. Walcott, B., Reeder, R. J., Frankel, R. B. 1982. Science 218:69597

46. Lins de Barros, H. G. P., Esquivel, D. M. S., Danon, J., de Oliveira, L. P. H. 1982. An. Acad. Bras. Cienc. $54: 258-59$

47. Lowenslam, H. A. 1962. Geol. Soc. Am. Bull. 73:435-38

48. Lowenstam, H. A, 1981. Srience 211: 1126-31

49. Mackay, A. L. 1960 . In Reartivity of Solids, ed. J. H. DeBoer, pp. 571-83. Amsterdam : Elsevier

50. Martin, H., Lindauer, M. 1977. J. Comp. Physiol 122:145-88

51. Mather, J., Baker, R. 1981. Nature 291: $152-54$

52. Matsuda, T., Endo, J., Osakabe, N., Tonomura, A., Arii, T. 1983. Nature 302: $411-12$

53. Moench, T. T., Konetzka, W. A. 1978. Arch. Microbiol. 119:203-12

54. Morrish, A. H. 1968. The Physical Principles of Magnetism. New York: Wiley. $680 \mathrm{pp}$.

55. Needham, J. 1962. Science and Civilization in China, 4(1):231-334. Cambridge: Cambridge Univ. Press

56. Perry, A., Bauer, G. B., Dizon, A. S. 1981. Trans. Am. Geophys. Union 62:850

57. Phillips, J. B. 1977. J. Comp. Physiol. A. $121: 273-88$

58. Presti, D., Pettigrew, J. D. 1980. Nature 285:99-101

59. Purcell, E. M. 1977. Am. J. Phys. 45: 3-10

60. Quinn, T. P. 1980. J. Comp. Physiol. 137:243-48

61. Rosenblatt, C., Torres de Araujo, F. F., Frankel, R. B. 1982. Biophys. J.40:83-85

62. Rosenblatt, $C$., Torres de Araujo, F. F., Frankel, R. B. 1982. J. Appl. Phys. 53:2727-29

63. Stoner, E. C. 1972. Encyclopedia Brittanica, 14:584-86. Chicago: Benton

64. Tamaura, Y., Ho, K., Katsura, T. 1983. J. Chem. Soc. Dalton Trans. 189-94

65. Towe, K. M., Lowenstam, H. A. 1967. J. Ultrastruct. Res. 17:1-13

66. Towe, K. M.. Moench, T. T. 1981. Earlh Planet. Sci. Lett. $52: 213-20$ 
67. Walcott, C. 1978. See Rel. 38, pp. 14351

68. Walcolt, C. 1980. HEELE Trans. Magn. $\mathrm{M} \wedge(;-16: 100) 8 \quad 13$

69. Walcott, C., Ciould, J. L., Kirschvink, J. L. 1979. Science 205: 1027-29

70. Walcott, C., Green, R. 1974. Science 184: $180-82$

71. Walker, M. M., Dizon, A. S. 1981. Trans. Am. Geophys. Union 62:850

72. Webh, J. 198.3. In Biomineralization and Biolngical Metal Acemmulators, ed. P.
Wesibroek, E: W. de Jong. pp. 413 22.

New York: Rcidel

73. Wilıschko, W. 1978. See Rer. 38, ne. 302 10

74. Wiltschko, W., Wiltschko, R. 1972. Science 176: 62-64

75. Yorke, E:. D. 1981. J. Theor. Biol. $89: 53337$

76. Zoeger, J., Dunn, J. R., Fuller. M. 1981. Science 213:892 94 